\title{
Roteiro das Minas
}

\section{e Pontos de Interesse Mineiro e Geológico de Portugal}

\author{
Joana Rodrigues \\ Geopark Naturtejo Mundial da UNESCO
}

\section{CITAÇÃO}

Rodrigues, J.(2021)

Roteiro das Minas e Pontos de Interesse

Mineiro e Geológico de Portugal,

Rev. Ciência Elem., v9(01):012.

doi.org/10.24927/rce2021.012

\section{EDITOR}

José Ferreira Gomes,

Universidade do Porto

\section{EDITOR CONVIDADO}

Jorge Manuel Canhoto

Universidade de Coimbra

\section{RECEBIDO EM}

09 de novembro de 2020

\section{ACEITE EM}

07 de dezembro de 2020

\section{PUBLICADO EM}

15 de março de 2021

\section{COPYRIGHT}

(C) Casa das Ciências 2021.

Este artigo é de acesso livre, distribuído sob licença Creative

Commons com a designação CC-BY-NC-SA 4.0, que permite a utilização e a partilha para fins não comerciais, desde que citado o autor e a fonte original do artigo.

rce.casadasciencias.org

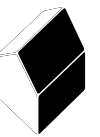

O "Roteiro das Minas e Pontos de Interesse Mineiro e Geológico de Portugal" é uma plataforma de divulgação e promoção do património mineiro e geológico de Portugal para além de uma ferramenta educativa nessas áreas do conhecimento. Reúne diversos parceiros de Norte a Sul do país, entre os quais museus, centros de interpretação, centros de ciência, geoparques, minas e locais de interesse geológico.

O "Roteiro das Minas e Pontos de Interesse Mineiro e Geológico de Portugal" (www.roteirodeminas.pt), desenvolvido pela DGEG (Direção Geral de Energia e Geologia ), pela EDM (Empresa de Desenvolvimento Mineiro, SA) e por trinta e oito entidades, que acabou de comemorar os seus dez anos de "visibilidade pública"1, 2. Pretende, entre outros objetivos, contribuir para o desenvolvimento local através de iniciativas de salvaguarda e rentabilização do património geológico e mineiro e a promoção do conhecimento científico nas áreas em que essas entidades intervêm.

0 Roteiro integra um vasto leque de entidades com territórios, recursos, abordagens e enquadramento institucional diversificados, estando envolvidas autarquias, associações, universidades, institutos politécnicos, fundações, institutos públicos e empresas públicas e privadas, o que sem dúvida enriquece a oferta e a torna mais interessante. As suas atividades refletem naturalmente essa diversidade, o que proporciona experiências sempre diferentes e únicas aos que nelas participam.

Os parceiros que o integram têm a gestão direta sobre 41 Locais (TABELA 1) e mais de 130 Pontos com relevância mineira ou geológica; assegurando as condições de elegibilidade onde se destacam a sua competência científica (interna ou protocolada) e a capacidade de apoiar a visitação e a interpretação desses pontos pelos públicos-alvo definidos, onde os estudantes, professores e outros agentes educativos têm especial relevância, mas que incluem também os especialistas e as famílias. Os Locais representados no Roteiro são de carácter lúdico, cultural, pedagógico e científico e apresentam algum tipo de estrutura de apoio à visita.

Por sua vez, as atividades do Roteiro e dos seus parceiros enquadram-se em diferentes áreas de intervenção das políticas públicas:

- na estratégia nacional definida para os recursos geológicos, visando promover a sua competitividade e o crescimento da economia através do aprovisionamento sustentável e eco eficiente de matérias-primas e a responsabilidade social e ambiental, a reabilitação do legado mineiro originado por um sector extrativo de séculos;

- na conservação da natureza e da biodiversidade, tendo em consideração o desafio de 
promover a valorizar esse património e adequa-lo ao usufruto do espaço e dos recursos, na perspetiva do seu valor e contributo para o desenvolvimento local e regional;

- no património cultural na exata medida em que os objetivos do projeto concretizam os valores de "memória, antiguidade, autenticidade (...) ou exemplaridade", refletindo o interesse cultural relevante dos bens patrimoniais culturais e a sua fruição tais como minas abandonadas, coleções geológicas, património móvel;

- no estímulo pela educação/formação (formal, não formal ou até informal) e pelo saber científico com vista a formar cidadãos informados, participativos e comprometidos com a sua quota-parte na promoção de um desenvolvimento sustentável;

- e, na perspetiva da oferta turística, através da potenciação de ativos (diferenciadores, emergentes e qualificadores) que visam a sustentabilidade e a competitividade dos destinos, correspondendo ao que já hoje se desenvolve no designado turismo de natureza, turismo científico, ou turismo industrial - com base nas suas características, enriquecendo a experiência turística e acrescentando valor à oferta do território.

\section{Património Geológico e Geomineiro de Portugal: Plataforma online}

Portugal tem uma história geológica rica, cujo testemunho inclui evidências da deriva continental e formação de montanhas, bem como da evolução da vida, entre muitos outros episódios de carácter geológico, preservados em inúmeros pontos de interesse espalhados pelo país. Também a história da exploração dos recursos geológicos é longa, com vestígios mineiros que remontam desde a Idade do Ferro ao período romano, existindo explorações ativas nos dias de hoje. A Geodiversidade de Portugal reflete-se também numa grande variedade de águas subterrâneas, com inúmeras águas minero-medicinais e termais já reconhecidas pelo naturalista Plínio, o Velho, na sua obra "História Natural" (Livro 2 Cap. 103; 77-79 d.C.).

Garantir a salvaguarda, rentabilização e manutenção deste património, bem como a segurança dos locais, é um dos objetivos do Roteiro das Minas e Pontos de Interesse Mineiro e Geológico de Portugal, assim como contribuir para um desenvolvimento local sustentável, a partir de um conjunto de iniciativas inovadoras e diferenciadoras dos territórios, assentes no património geológico e mineiro.

Do ponto de vista ambiental e social, pretende-se também promover a vivência dos espaços pelas populações residentes, nomeadamente dos que foram alvo de intervenção da EDM. Por outro lado, torna-se imperativo consciencializar para a exploração sustentável dos recursos geológicos e melhorar a imagem sobre a atividade mineira, prejudicada por maus exemplos de gestão ambiental.

Como referido, o Roteiro inclui atualmente 41 locais, da responsabilidade de 38 Parceiros, com uma vasta oferta de mais de 130 Pontos de interesse por todo o país, distribuídos de Norte a Sul de Portugal Continental, bem como no Arquipélago dos Açores (FIGURA 1; TABELA 1). 


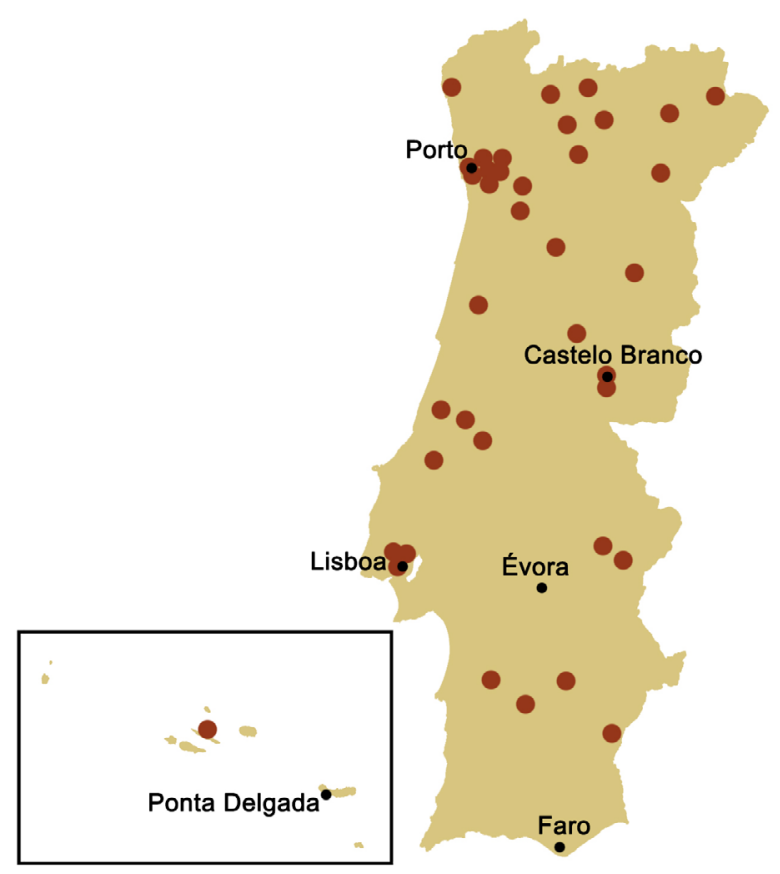

FIGURA 1. Distribuição dos Locais do Roteiro das Minas e Pontos de Interesse Mineiro e Geológico de Portugal.

A exploração mineira na antiguidade é o tema central de locais como o Parque Arqueológico do Vale do Terva (FIGURA 2 A)), o Complexo Mineiro Romano de Tresminas (FIGURA 2B)) ou as Minas de Castromil. Existem ainda outros importantes espaços mineiros que laboraram até ao século XX, como por exemplo, a Mina de São Domingos (FIGURA 2C)), as Minas de Argozelo (FIGURA 2D)) ou até as Minas de Aljustrel (FIGURA 2E)) e da Panasqueira, ainda em laboração, e que documentam períodos incontornáveis da História de Portugal, como por exemplo o período romano ou as duas grandes guerras mundiais e a importância estratégica de minérios de volfrâmio, estanho e cobre, entre outros.
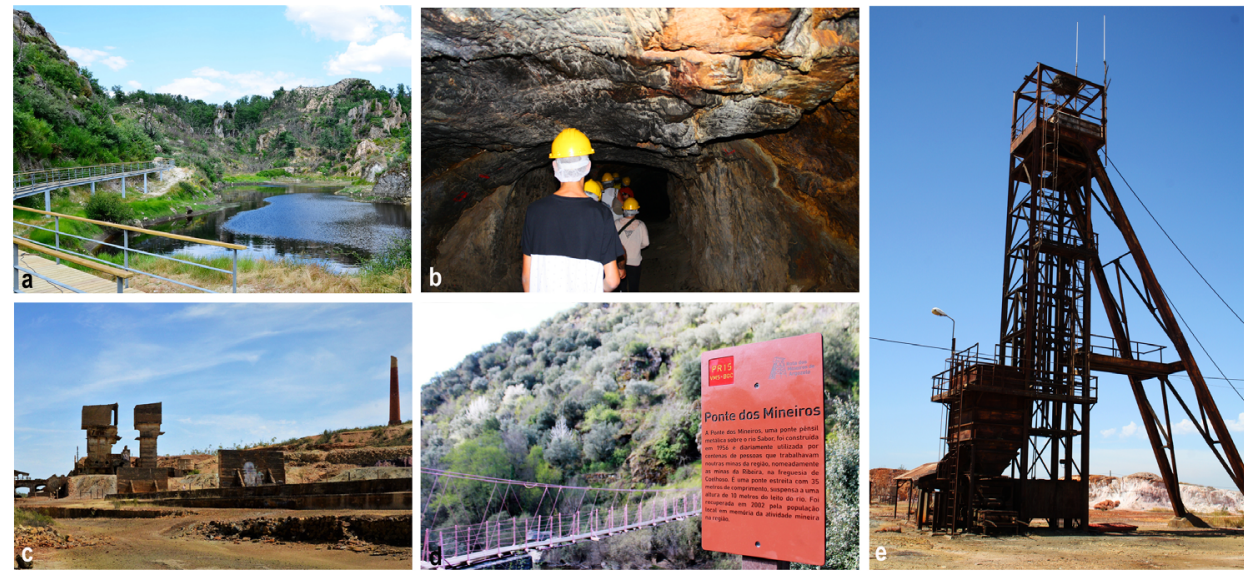

FIGURA 2. Exemplos de Locais: A) Parque Arqueológico do Vale do Terva. B) Complexo Mineiro Romano de Tresminas. C) Minas de S. Domingos. D) Minas de Argozelo. E) Minas de Aljustrel (créditos A), C), D) - Bernardo Lemos; B) e E) - Joana Rodrigues).

Em termos de musealização, são vários os museus e centros que interpretam contextos específicos de atividade mineira, como o Museu do Volfrâmio de Cerva (FIGURA 3A)), 
Centro Interpretativo das Minas da Borralha (FIGURA 3B)), Museu do Ferro e da Região de Moncorvo (FIGURA 3C)), Museu Mineiro de São Pedro da Cova (FIGURA 3D)) ou a Mina do Lousal, sendo que este último exemplo, combina a história mineira com um Centro de Ciência Viva.

A exploração de recursos geológicos não metálicos (como o sal-gema, a ardósia, calcário, o granito, o mármore, o quartzo, o tufo calcário, entre outros), assim como a sua transformação, estão em destaque em vários locais, nomeadamente no Ecomuseu Salinas de Rio Maior (FIGURA 4A)), Museu da Lousa (FIGURA 4B)), Museu da Pedra do Município de Cantanhede (FIGURA 4C)), Museu do Canteiro (FIGURA 4D)), Museu do Cimento da Fábrica Maceira-Liz (FIGURA 4E)), Museu da Pedra do Marco de Canaveses, Museu do Mármore de Vila Viçosa, e no Museu do Quartzo ou Grutas de Lapas.

Mais uma vez, no Museu do Instituto Superior de Engenharia do Porto (FIGURA 5A)), ou no Núcleo Museológico do Departamento de Engenharia de Minas da Faculdade de Engenharia da Universidade do Porto, o enfoque é dado também às técnicas de exploração mineira, mas nestes casos, incluindo também o seu contexto na história do seu ensino.
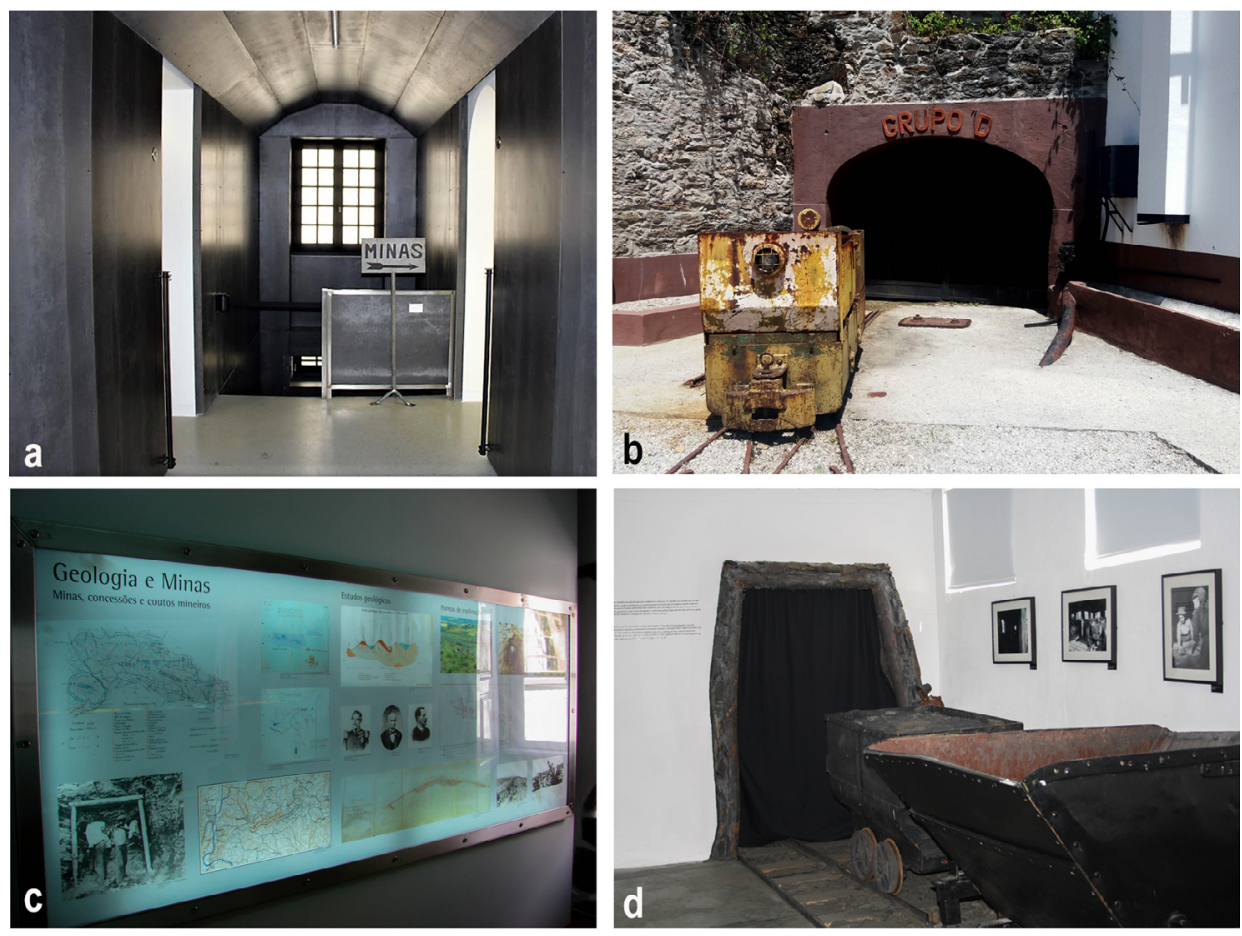

FIGURA 3. Exemplos de Locais: A) Museu do Volfrâmio de Cerva. B) Centro Interpretativo das Minas da Borralha. C) Museu do Ferro e da Região de Moncorvo. D) Museu Mineiro de São Pedro da Cova. (créditos A) - Museu do Volfrâmio de Cerva; B), C), D) - Joana Rodrigues). 

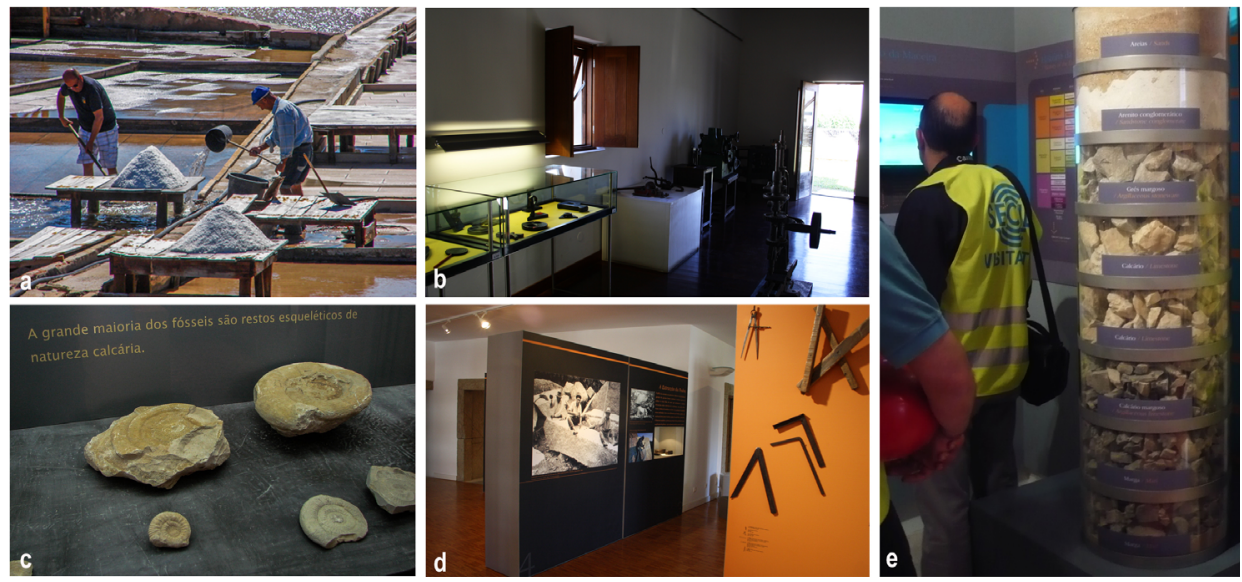

FIGURA 4. Exemplos de Locais: A) Ecomuseu Salinas de Rio Maior. B) Museu da Lousa. C) Museu da Pedra do Município de Cantanhede. D) Museu do Canteiro. E) Museu do Cimento da Fábrica Maceira-Liz. (créditos Joana Rodrigues).

O ROTEIRO inclui ainda coleções geológicas de referência, como as do Museu Geológico (FIGURA 5B)), Museu Nacional de História Natural e da Ciência, Museus de Geociências do Instituto Superior Técnico, Museu de Jazigos Minerais Portugueses, e Museu de Geologia da Universidade de Trás-os-Montes e Alto Douro. Locais como o Centro Ciência Viva do Alviela - Carsoscópio ou o Centro de Interpretação Científico-Ambiental das Grutas da Moeda (FIGURA 5C)), centram-se na interpretação das morfologias cársicas do Maciço Estremenho.
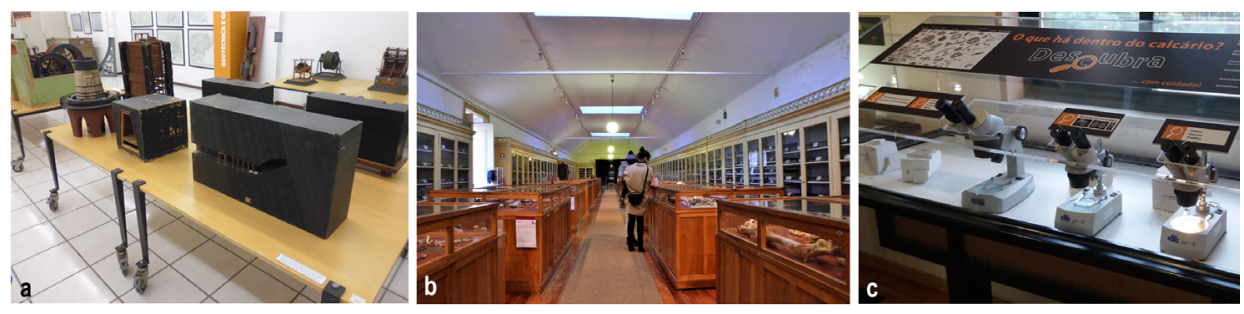

FIGURA 5. Exemplos de Locais: A) Museu do Instituto Superior de Engenharia do Porto. B) Museu Geológico. C) Centro de Interpretação Científico-Ambiental das Grutas da Moeda. (créditos A), C) - Joana Rodrigues, C) - Bernardo Lemos).

Além dos Centros Ciência Viva do Lousal e Alviela, também está incluído o CCV de Estremoz, com uma abordagem interativa dedicada aos processos passados e atuais da evolução do planeta.

Inúmeros locais de interesse geológico e geomineiro estão distribuídos pelos cinco Geoparques Mundiais da UNESCO Portugueses: Naturtejo (FIGURA 6A)), Arouca, Açores (FIGURA 6B)), Terras de Cavaleiros, Estrela e pelo projeto de Geoparque Litoral de Viana do Castelo. Muito mais do que áreas de relevância patrimonial, os geoparques são territórios dinâmicos dos quais as comunidades locais fazem parte e onde a geodiversidade, a natureza, a história e a cultura se entrelaçam.

O ROTEIRO inclui ainda pontos organizados em circuitos como é o caso do Trilho Geológico de Beja (FIGURA 6C)), Rota do Mármore, Passeio Geológico da Foz do Douro (FIGURA 6D)), ou dos Percursos do Parque Paleozóico de Valongo (FIGURA 6E)).

Até ao final do ano de 2020 é previsível contar com a adesão de mais três locais de grande interesse para a problemática que tem vindo a ser abordada no ROTEIRO, nomea- 
damente a Mina de Sal Gema (Loulé), o Monumento Natural das Pegadas de Dinossáurios da Serra de Aire (Ourém) e as Minas do Braçal (Sever do Vouga).
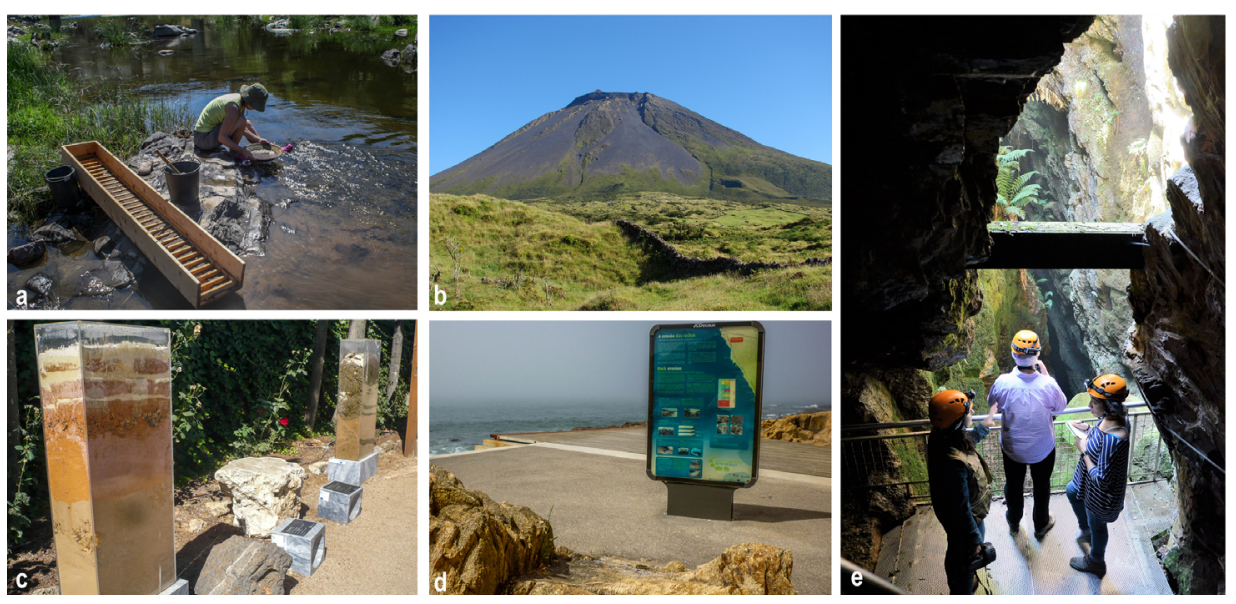

FIGURA 6. Exemplos de Locais: A) Geopark Naturtejo. B) Açores Geopark. C) Trilho Geológico de Beja. D) Passeio Geológico da Foz do Douro. E) Percursos do Parque Paleozóico de Valongo (créditos A - Geopark Naturtejo, B), C), D) - Joana Rodrigues, E) - Bernardo Lemos).

A plataforma www.roteirodeminas.pt apresenta detalhadamente os Parceiros e os Locais/Pontos que lhes estão associados, com a descrição de cada um, informação científica, dados logísticos e informação turística que permitem a preparação da visita (FIGURA 7).

$\ll$ retornar ao local

Monumento Natural das Portas de Ródão, Santana/Vila Velha de Ródão

No Monumento Natural das Portas do Rodão, o maior rio da Península Ibérica, o Tejo, corre entrincheirado e submisso entre gigantes quartzíticos. A erosão fluvial terá avançado à velocidade de apenas $10 \mathrm{~cm}$ por cada 1000 anos, nos últimos 2,6 milhöes de anos. Tanta beleza geológica sỏ poderia ter sido aproveitada como habitat para as espécies vegetais e animais mais singulares pelo Homem, desde há mais de 150000 anos. Trata-se de um dos ex-libris do Geopark Naturtejo, observável da Ponte do Ródão, do parque de merendas da Foz do Envarique, o Miradouro do Castelo do Rei Wamba e do Miradouro da Sra da Achada.

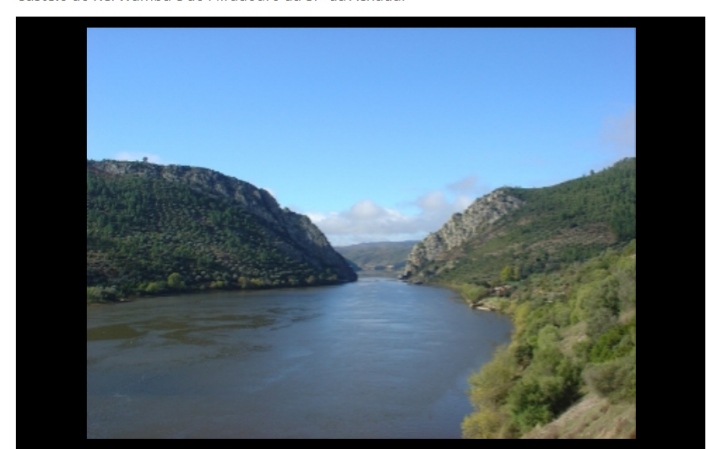

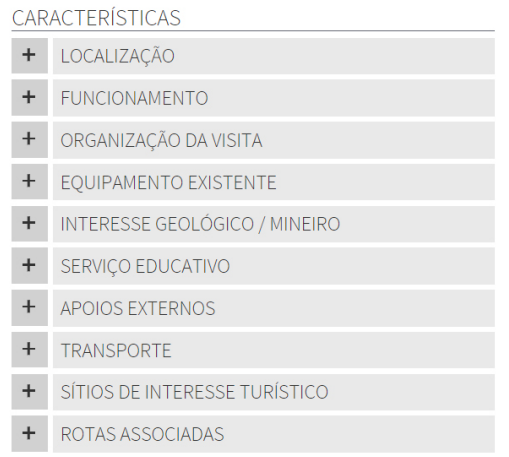

FIGURA 7. Plataforma do ROTEIRO DE MINAS: exemplo do Ponto "Monumento Natural das Portas de Ródão", do Local "Geopark Naturtejo, Geopark mundial da Unesco.

Está disponível uma ferramenta de construção de itinerários e rotas georreferenciados, designada de "A Minha Viagem". Existem também Rotas temáticas pré-definidas, de nível regional e nacional, que integram pontos de diversos parceiros, designadamente Rota dos Geoparques em Portugal, Rota do Volfrâmio, Rota da Faixa Piritosa Ibérica, Rota Romana do Ouro no Norte de Portugal ou Geodescobertas na Área Metropolitana do Porto (FIGURA 8). Existe uma área dedicada à visitação turística, com informação sobre transportes, aloja- 
mento, restauração e outros equipamentos de apoio.

A plataforma inclui ainda notícias sobre a atividade dos parceiros e em rede, nomeadamente de exposições temporárias, muitas delas destinadas ao público escolar.

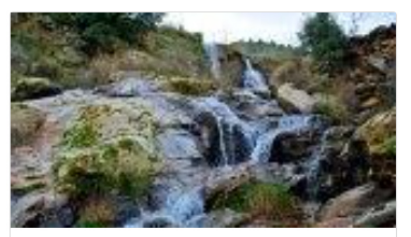

Geoparques em Portugal

(Rota em desenvolvimento) Os Geoparques Mundiais da UNESCO são territórios com locais e paisagens de importância geológica internacional, que ... Lert

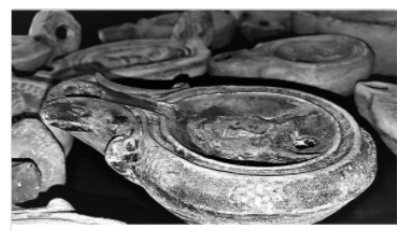

Rota Romana do Ouro no Norte de Portugal

A Rota Romana do Ouro no Norte de Portugal é uma

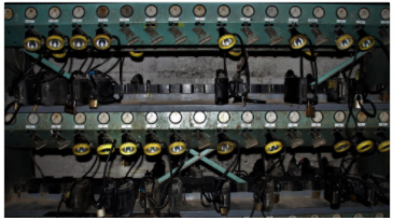

Rota do Volfrâmio

A história do século XX fica profundamente marcada pela corrida ao armamento e pelas duas Guerras Mundiais que assolaram o continente europeu.... Ler +
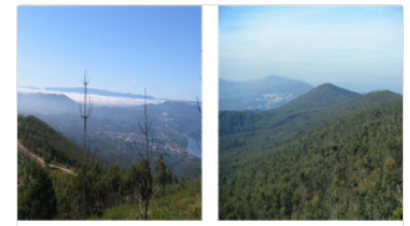

Geodescobertas na Área Metropolitana do Porto

Situados na área metropolitana do Porto, os

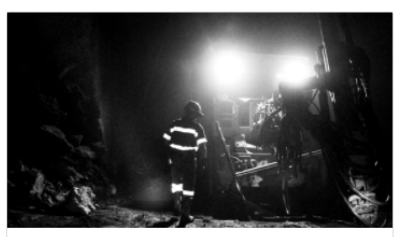

Rota da Faixa Piritosa Ibérica

A Rota da Faixa Piritosa lbérica é um percurso temático de turismo mineiro e geológico dedicado Faixa Piritosa Ibérica, considerada uma das .. Lert

FIGURA 8. Plataforma do ROTEIRO DE MINAS: Rotas temáticas.

\section{Oferta Educativa}

Sendo um dos objetivos do Roteiro das Minas e Pontos de Interesse Mineiro e Geológico de Portugal a promoção do conhecimento e da literacia científica, com especial incidência na população escolar, a plataforma apresenta um botão de "Serviço Educativo" com a descrição das atividades disponíveis em cada Local, assim como aspetos logísticos para a organização das visitas, relativos à duração, os custos e contactos.

Desde 2015, a oferta educativa dos parceiros tem sido compilada no guia "Serviços educativos e visitas escolares" (FIGURA 9), uma ferramenta atualizada e editada anualmente no início de cada ano letivo ${ }^{4}$. 0 guia reúne centenas de iniciativas, por todo o país, incluindo visitas a museus e centros de interpretação, geossítios, grutas, minas, pedreiras, exposições interativas, realização de ateliês e percursos pedestres, visionamento de documentários, entre muitas outras atividades. Estão também disponíveis informações sobre os níveis de ensino a que se destinam as atividades, as disciplinas em que enquadram, os principais temas a abordar, e os objetivos que se pretendem atingir, auxiliando os professores na articulação dos conteúdos. Existem atividades desde o Pré-escolar até ao Ensino Superior, passando pelo Ensino Profissional e por atividades para alunos com Necessidade Educativas Especiais, com conteúdos e estratégias adaptadas.

A última edição, com o título “Recursos Educativos - 2020/2021" (FIGURA 9), foi lançada no início de Setembro e o e-book foi difundido para todas as escolas do país com o apoio da Direcção Geral de Educação, estando disponível no sítio do ROTEIRO. Devido às contingências impostas pela atual situação pandémica de COVID-19, a mais recente edição inclui, não só as habituais atividades presenciais, como também atividades não presenciais. As restrições impostas para a contenção da transmissão do novo coronavírus da síndrome 
respiratória aguda grave 2 (SARS-CoV-2), condicionam as aulas práticas e de campo e que em vários momentos impõem o ensino à distância. Aproveitando a oportunidade de repensar estratégias e a necessidade de dar resposta aos desafios que professores e alunos enfrentam, no presente ano de 2020, os parceiros reuniram propostas educativas à distância, como palestras e apresentações através de videoconferências, disponibilizando também uma grande variedade de recursos online. Destacam-se ferramentas como filmes, documentários, jogos, passatempos, visitas virtuais, softwares aplicativos (Apps), livros digitais, museus virtuais e materiais de apoio digitais como dossiers temáticos, módulos de ensino, cadernos de atividades, brochuras ou folhetos.

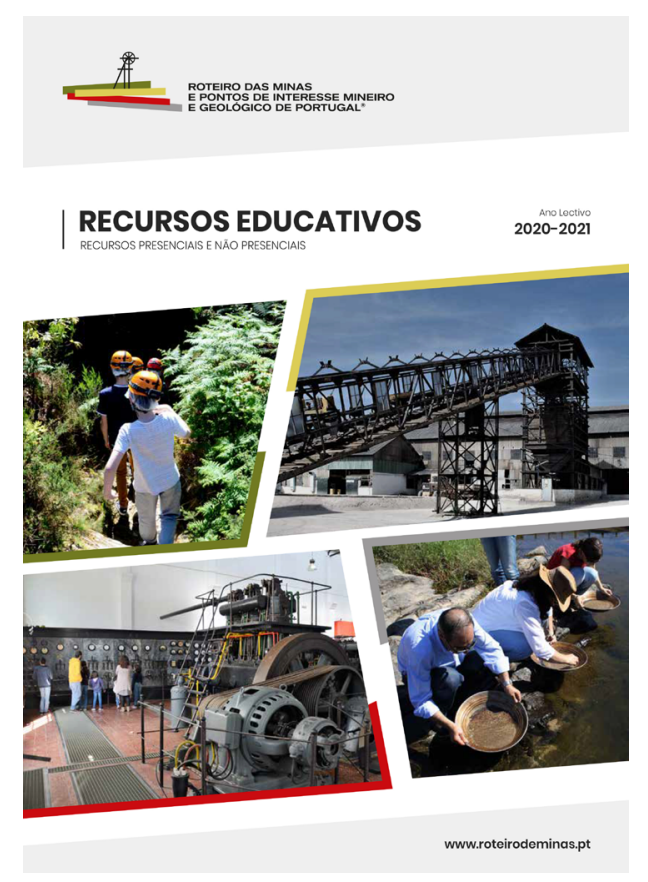

FIGURA 9. Capa do Guia "Recursos Educativos 2020/2021. 


\section{Testemunho}

A pandemia, que neste momento a todos afeta direta ou indiretamente, tem um forte impacto nas atividades realizadas em contexto escolar. No que respeita ao ensino das ciências experimentais, o desafio maior passa pela gestão das dinâmicas implementadas em sala de aula, uma vez que quaisquer atividades em que os alunos deixem de estar confinados à sua secretária podem pôr em causa o necessário distanciamento social. Acresce ainda a necessidade de se verificar, a cada momento, que os alunos não partilham os materiais manipulados durante os trabalhos propostos. Contudo, e em particular no caso da Geologia, estes constrangimentos podem ser atenuados graças à possibilidade de fazer (as sempre desejáveis) aulas no exterior, ou pedir aos alunos para trazerem as suas próprias amostras de mão de rochas, minerais e/ou fósseis. Pode-se ainda tirar partido das tecnologias de cada um (quando a idade o permite), usando os telemóveis para realizar a sua própria coleção de fotografias das amostras de mão disponíveis na escola, visualizar e discutir filmes sobre os temas abordados nas aulas, realizar atividades/jogos didáticos com instrumentos/materiais - não partilháveis - trazidos por cada aluno (telemóveis, lupas, post-it, dados, cartões, entre outros) e, finalmente, realizando algumas atividades experimentais de modelação análoga de fenómenos geológicos durante os quais o professor distribui cuidadosamente as tarefas a realizar por cada aluno de modo a que todos participem, em segurança, executando, recolhendo dados e discutindo os fenómenos estudados.

Testemunho da Professora Helena Moita de Deus, docente da E.B 2,3 de Ruy Belo (Monte Abraão, Sintra) relativamente aos principais desafios do ensino da Geologia na atual situação pandémica de COVID-19.

\section{Atividades em Rede do Roteiro de Minas}

Inicialmente o Roteiro das Minas e Pontos de Interesse Mineiro e Geológico de Portugal privilegiou a visibilidade das iniciativas dos diferentes Parceiros, tendo sido percorrido um caminho onde foi crescente a componente de trabalho em rede. Além da plataforma online, os parceiros do Roteiro dinamizam atividades em rede ${ }^{3}$, designadamente através da partilha de boas práticas e recursos, onde se destaca o Encontro Anual. Este Encontro tem sido realizado ininterruptamente desde 2010, tendo já decorrido em vários Pontos do país e tendo adotado em 2020 um formato online, dado o contexto pandémico. Além do trabalho em rede, o evento tem integrado momentos com as comunidades e, mais recentemente, passou a incluir também sessões abertas ao público.

Todos os anos, a 'Semana dos Parceiros' apresenta um calendário diversificado que integra ações conjuntas e iniciativas únicas. Neste âmbito, foram produzidas - por exemplo - várias exposições itinerantes, como 'Carvão de Aço - Fotografias de Adriano Miranda', 'Rochas e Minerais - Norte de Portugal' ou '1ํㅡㄹ Encontro Fotográfico em Cavidades Artificiais' que circulam por todo o país, sobretudo através dos locais do Roteiro. 
TABELA 1. Lista de Locais integrados no das Minas e Pontos de Interesse Geológico e Mineiro de Portugal (atualizado em Setembro 2020).

\begin{tabular}{|c|c|}
\hline Locais & Localização \\
\hline Arouca Geopark & Arouca \\
\hline Centro Ciência Viva de Estremoz & Estremoz \\
\hline Centro Ciência Viva do Alviela & Alcanena \\
\hline $\begin{array}{l}\text { Centro de Interpretação Científico- } \\
\text { Ambiental das Grutas da Moeda }\end{array}$ & Batalha \\
\hline Complexo Mineiro Romano de Tresminas & Vila Pouca de Aguiar \\
\hline Ecomuseu Salinas de Rio Maior & Rio Maior \\
\hline $\begin{array}{l}\text { Ecomuseu de Barroso, Centro } \\
\text { Interpretativo das Minas da Borralha }\end{array}$ & Montalegre \\
\hline Estrela Geopark & Guarda (sede) \\
\hline $\begin{array}{l}\text { Geopark Naturtejo, Geoparque Mundial da } \\
\text { UNESCO }\end{array}$ & Castelo Branco (sede) \\
\hline $\begin{array}{l}\text { Geopark Terras de Cavaleiros, Geoparque } \\
\text { Mundial da UNESCO }\end{array}$ & Macedo de Cavaleiros \\
\hline Geoparque Açores & R A Açores \\
\hline Geoparque Litoral de Viana do Castelo & Viana do Castelo \\
\hline Grutas de Lapas & Torres Novas \\
\hline Loja de Cristais das Minas da Panasqueira & Covilhã \\
\hline Mina de São Domingos & Mértola \\
\hline Mina do Lousal & Grândola \\
\hline Minas de Aljustrel & Aljustrel \\
\hline Minas de Argozelo & Vimioso \\
\hline Minas de Castromil & Paredes \\
\hline Museu da FEUP & Porto \\
\hline Museu da Lousa & Valongo \\
\hline Museu da Pedra do Marco de Canaveses & Marco de Canaveses \\
\hline $\begin{array}{l}\text { Museu da Pedra do Município de } \\
\text { Cantanhede }\end{array}$ & Cantanhede \\
\hline Museu de Geologia da UTAD & Vila Real \\
\hline Museu de Jazigos Minerais Portugueses & Matosinhos \\
\hline Museu do Canteiro & Castelo Branco \\
\hline Museu do Cimento da Fábrica Maceira-Liz & Leiria \\
\hline Museu do Ferro e da Região de Moncorvo & Torre de Moncorvo \\
\hline Museu do ISEP & Porto \\
\hline Museu do Mármore de Vila Viçosa & Vila Viçosa \\
\hline $\begin{array}{l}\text { Museu do Quartzo, Centro de } \\
\text { Interpretação Galopim de Carvalho }\end{array}$ & Viseu \\
\hline Museu do Volfrâmio de Cerva & Ribeira de Pena \\
\hline Museus de Geociências do IST & Lisboa \\
\hline Museu Geológico & Lisboa \\
\hline Museu Mineiro de São Pedro da Cova & Gondomar \\
\hline
\end{tabular}




\begin{tabular}{|l|l|}
\hline $\begin{array}{l}\text { Museu Nacional de História Natural e da } \\
\text { Ciência }\end{array}$ & Lisboa \\
\hline Parque Arqueológico do Vale do Terva & Boticas \\
\hline Parque Paleozóico de Valongo & Valongo \\
\hline Passeio Geológico da Foz do Douro & Porto \\
\hline Rota do Mármore & Vila Viçosa \\
\hline Trilho Geológico de Beja & Beja \\
\hline
\end{tabular}

Entre outras iniciativas que têm vindo a ser desenvolvidas, destacamos a criação do guia “Minas e Geologia Norte Portugal", referente à região Norte do país e publicado com o apoio da Entidade Regional de Turismo Porto e Norte de Portugal, onde se associam os recursos geológicos e mineiros ao restante património material e imaterial regional. A associação ao Grupo Dinamizador da Rede Portuguesa de Turismo Industrial desde o início dos seus trabalhos é outro vetor de intervenção da equipa do, em colaboração com o Turismo de Portugal e outros atores que partilham interesses na promoção de uma oferta diferenciadora do turismo em Portugal. Em termos internacionais o está associado à Rede Ibérica de Espaços Geomineiros.

Toda a atividade do pode ser acompanhada através da sua Newsletter, sítio e nas redes sociais.

\section{Conclusão}

O Roteiro de Minas e Pontos de Interesse Geológico e Mineiro de Portugal inclui uma grande variedade de instituições por todo o país que se dedicam à proteção, valorização e divulgação do Património Geológico e Mineiro de Portugal. Além do relevante trabalho feito por cada um dos Parceiros, ao longo dos últimos 10 anos têm vindo a ser desenvolvidas estratégias que têm permitido aproximar o público desta temática, e desse modo, contribuir para o desenvolvimento local, sobretudo em territórios de baixa densidade populacional, onde os desafios presentes se colocam com grande acuidade.

Do ponto de vista educativo, o Roteiro constitui uma poderosa ferramenta ao dispor de professores e alunos, não só para a realização de visitas e atividades práticas, mas também para a exploração dos mais diversos temas relacionados com a Geologia, Geodiversidade e a Exploração Mineira em Portugal.

As restrições impostas pela atual situação de pandemia de COVID-19 têm obrigado o Roteiro e os Parceiros a procurar novas soluções e formas de ultrapassar os grandes constrangimentos que se colocam. Tentando dar resposta às necessidades das comunidades educativas, está a ser feita uma maior aposta no contexto digital, na disponibilização de conteúdos e recursos que possam, por um lado, apoiar o ensino à distância, e por outro, colmatar a falta de visitas e aulas de campo.

\section{Agradecimento}

Um especial agradecimento ao Bernardo Lemos pelo apoio incansável e pela preciosa contribuição para este trabalho.

Agradecemos à Professora Helena Moita de Deus pelo testemunho prestado no âmbito deste trabalho. Remetemos um profundo agradecimento a todos os Parceiros do Roteiro 
das Minas e Pontos de Interesse Mineiro e Geológico de Portugal, à DGEG e à EDM por todo o apoio e pelo trabalho em rede construtivo ao longo de mais de 10 anos.

\section{REFERÊNCIAS}

${ }^{1}$ LEMOS, J., Por um "Roteiro das Minas e Pontos de Interesse Geológivo e Mineiro de Portugal". In: P. Florido \& I. Rábano (eds.). Una visión multidisciplinar del patrimonio geológico y minero. Cuadernos del Museo Geominero, no 12 . Instituto Geológico y Minero de España, Madrid, 417-423. 2010.

2LEMOS, J. B., \& FALÉ, P., O "Roteiro das minas e pontos de interesse mineiro e geológico de Portugal" - uma realidade. In Macías, E. (coord.) Una apuesta por el desarrollo local sostenible, Universidad de Huelva, 937-941. 2010.

${ }^{3} \mathrm{PAZ}$, A. et al., The "Guide of the Portuguese geological and mines sites": an example of institutional cooperation. International Congress Arouca 2011: Geotourism in Action: 203-203. 2011.

${ }^{4}$ RODRIGUES, J. \& FALÉ, P., Guia dos «Serviços Educativos e Visitas Escolares» do de Minas e Pontos de Interesse Geológico de Portugal. III Encontro da Casa das Ciências. Livro de Resumos., Porto, 74-75. 2016. 